\title{
AVALIAÇÃO SAZONAL DAS ÁGUAS DO RESERVATÓRIO DA USINA HIDRELÉTRICA CAÇU NO MUNICÍPIO DE CAÇU, GOIÁS
}

\author{
Isabel Rodrigues da Rocha ${ }^{1}$ \\ João Batista Pereira Cabral ${ }^{2}$ \\ Pollyanna Faria Nogueira ${ }^{3}$ \\ Assunção Andrade de Barcelos ${ }^{4}$
}

Resumo: O reservatório da Usina Hidrelétrica (UHE) de Caçu está localizado na bacia hidrográfica do Rio Claro, região Sudoeste do estado de Goiás. O objetivo deste trabalho foi avaliar a qualidade das águas do reservatório da UHE Caçu em períodos distintos do Cerrado brasileiro, e realizar o enquadramento do corpo d'água, de acordo com a Resolução CONAMA 357/05. Os parâmetros físicos e químicos avaliados foram condutividade elétrica, oxigênio dissolvido, pH (Potencial Hidrogeniônico), temperatura da água, total de sólidos dissolvidos e turbidez. As coletas de dados dos pontos amostrados foram realizadas nos dias $17 / 01 / 2012,10 / 07 / 2012,23 / 01 / 2013$ e 30/07/2013. Os resultados obtidos foram discutidos e comparados com base nos limites estabelecidos pelo órgão ambiental CONAMA, na resolução № 357, de 17 de março de 2005. Os resultados foram avaliados quanto à conformidade, sendo verificados pontos que se enquadram nas Classes 1, 2 e 3; somente alguns pontos e algumas variáveis se enquadraram na classe 4. Em termos gerais, as condições atuais apresentam água de boa qualidade, para uso e dessedentação de animais, segundo os pontos amostrados e analisados. De acordo com os dados avaliados, as águas do reservatório da UHE Caçu podem ser classificados para turbidez como, nas classes 3 e 4 para o trecho rio, classe 2 para o trecho transição, e na classe 1 para o trecho lago, no período de janeiro de 2013. As demais variáveis, estabelecem limites individuais idênticos para todas as classes de águas doces.

Palavras-chave: Reservatório; Recursos Hídricos; Limnologia; Resolução Conama.

\section{EVALUATION OF SEASONAL WATERS RESERVOIR OF HYDROELECTRIC POWER PLANT CAÇU IN THE MUNICIPALITY OF CAÇU, GOIÁS}

Abstract: The reservoir of the Hydroelectric Power Plant (HPP) of Caçu is located in the watershed of the Rio Claro, Southwest region of the state of Goiás. The objective of this study was to evaluate the water quality of the reservoir HPP Caçu in different periods of the

1. Doutoranda do Programa de Pós-Graduação em Geografia (PPGEO/IESA), Universidade Federal de Goiás (isabel8720@gmail.com).

2. Professor e Pesquisador do Programa de Pós-Graduação em Geografia (POSGEO-Jataí), Universidade Federal de Goiás, Regional Jataí (jbcabral2000@yahoo.com.br).

3. Mestre pelo Programa de Pós-Graduação em Geografia (POSGEO-Jataí), Universidade Federal de Goiás, Regional Jataí (pollypam@hotmail.com).

4. Mestrando do Programa de Pós-Graduação em Geografia (POSGEO-Jataí), Universidade Federal de Goiás, Regional Jataí (assuncaoa-barcelos@hotmail.com). 
Brazilian Cerrado, and perform the measure of the water body, according to CONAMA Resolution 357/05. The physical and chemical parameters evaluated were electrical conductivity, dissolved oxygen, $\mathrm{pH}$ (Potential hydrogenionic), water temperature, total dissolved solids and turbidity. The data collections of sample points were taken on days $17 / 01 / 2012,10 / 07 / 2012,23 / 01 / 2013$ and 07/30/2013. The results were discussed and compared based on limits set by the environmental agency CONAMA Resolution № 357 on, March 17, 2005. The results were evaluated for conformity being checked points that fall within Classes 1, 2 and 3; only a few points and some variables fall into in the class 4. In general, current conditions have good water to use and watering livestock, according to the points sampled and analyzed. According to the data evaluated, the waters of the reservoir HPP Caçu can be classified as turbidity, in classes 3 and 4 for the river stretch, stretch class 2 for the transition, and the first class to stretch Lake, in the period from January 2013. The other variables, identical set individual limits for all classes of freshwaters.

Key words: Reservoir, Water Resources, Limnology, Resolution CONAMA.

\section{INTRODUÇÃO}

A respeito de diversos usos dos recursos naturais, talvez o da água seja o mais utilizado para inúmeras finalidades pela humanidade (CARVALHO, 2008). No Brasil e no mundo, a distribuição das águas é irregular, existindo regiões com abundância e outras com escassez, sendo que seu uso está diretamente ligado às reservas com disponibilidade líquida, pelas reservas continentais de lagos, rios, represas e águas subterrâneas (TUNDISI; MATSSAMURA TUNDISI, 2008).

Atualmente, a água é compreendida como fonte de valor econômico, essencial para a sobrevivência e desenvolvimento da sociedade, visto que as sociedades modernas continuam a se desenvolver, formando grandes centros urbanos e deixando de lado a preocupação em não contaminar o meio ambiente.

O abastecimento de água e seus diversos usos, como nas práticas agrícolas, são os que mais contribuem para sua escassez e contaminação (KOBIYAMA; MOTA; CORSEUIL, 2008). Segundo Carvalho (2008), não há como pensar em desenvolvimento sustentável sem pensar em água; porém, ele jamais será atingido sem quantidade suficiente e qualidade adequada.

Os rios são submetidos permanentemente aos impactos das atividades humanas, que têm vários níveis de magnitude, desde a construção de canais, desmatamento das matas de galerias, de APP (Área de Preservação Permanente) até a descarga de metais pesados, herbicidas, e um grande numero de substâncias orgânicas que se dissolvem na água. A 
utilização da água nas atividades antrópicas a tem deixado vulnerável a agressões, de poluição, assoreamento, entre outros impactos (TUNDISI; MATSUMURA TUNDISI, 2008).

Nos últimos anos, grandes empreendimentos hidráulicos têm sido instalados em vários rios no Brasil. Sobretudo pela extensa área territorial compreendendo grandes bacias hidrográficas, como do rio Paraná, rio São Francisco e Amazonas (TUNDISI; MATSUMURA TUNDISI, 2008).

No Brasil, a produção de energia a partir de reservatórios de usinas hidroelétricas é responsável por mais de $90 \%$ da energia consumida no país (ANEEL, 2005). Destacam-se, nesse contexto, grandes usinas como Balbina (AM), Sobradinho (BA), Corumbá (GO), Serra da Mesa (GO), Itaipu Binacional (PR), Ilha Solteira (SP), etc. As usinas são construídas para diversos usos, como geração de energia, abastecimento, equilíbrio de outros reservatórios e seu gerenciamento deve incorporar, além dos usos, custos e impactos, diretos e indiretos sobre o ambiente.

Com os novos empreendimentos hidroelétricos instalados em vários rios do Brasil, muito se tem estudado sobre seus impactos no meio ambiente, devido à grande importância para o planejamento do uso adequado da água. Isso porque, os recursos hídricos referentes à água são um bem econômico valioso para o país (REBOUÇAS, 2006).

O monitoramento, a partir, dos parâmetros físico-químicos como $\mathrm{pH}$, temperatura, condutividade elétrica, turbidez, entre outros parâmetros em águas doces, são necessários para determinar padrões de qualidade e, a partir de outras análises, ou outros tipos de investigação, pode-se descobrir o nível de degradação de uma bacia (ROCHA; CABRAL; BRAGA, 2014).

A Resolução CONAMA no 357, de 2005, foi criada para satisfazer e normalizar os padrões adequados à potabilidade das águas, que podem ser utilizadas para o abastecimento público, desde que passem por tratamento, após simples desinfecção, remoção ou inativação de organismos potencialmente patogênicos, além de apresentar condições de qualidade de corpos d'água, num determinado momento, em termos dos usos aceitáveis, com segurança adequada, frente às classes de qualidade. Atualmente, a resolução considera 13 classes de qualidade de águas, sendo 5 para águas doces, 4 para águas salobras e 4 para águas salinas, englobando as classes especiais. 
Diante disso, estudos envolvendo a qualidade da água de bacias hidrográficas, como na bacia hidrográfica do rio Claro, região sudoeste de Goiás, vem sendo objeto de pesquisas relativas à qualidade da água e outros componentes dos meios físico, biológico e antrópico.

De acordo com os trabalhos apresentado por Cabral et al. (2013), e Rocha, Cabral e Braga (2014), a bacia do rio Claro apresenta problemas ambientais devido a diminuição da cobertura vegetal de cerrado, aos impactos causados pelo uso extensivo e intensivo do solo para a prática de pecuária, produção agrícola e de cana de açúcar, alterando o regime ambiental da bacia.

O rio Claro é importante na sua região, pois, além do seu potencial hidroelétrico, é um rio que fornece água para as cidades, indústrias e lavouras. Nesta bacia foram instalados vários reservatórios importantes. Três desses reservatórios situam-se na região do baixo rio Claro, que são as UHEs Caçu, Barra dos Coqueiros e Foz do Rio Claro, considerados de médio porte, e outras de pequeno porte como a PCH (Pequenas Centrais Hidrelétricas) Jataí e Irara instalados na região do médio rio Claro (NOVELIS, 2005). Além dos empreendimentos já instalados, está prevista, para o futuro, a construção de empreendimentos de médio porte como as UHEs Ari Franco e Itaguaçu.

Portanto, a presente pesquisa teve por objetivo analisar a qualidade das águas em épocas sazonais típicas do cerrado brasileiro, no reservatório da Usina Hidrelétrica (UHE) Caçu, analisando espacialmente e temporalmente os dados limnológicos de condutividade elétrica, oxigênio dissolvido, $\mathrm{pH}$ (Potencial Hidrogeniônico), temperatura da água, total de sólidos dissolvidos e turbidez. As coletas foram feitas em quatro campanhas temporais, de janeiro e julho 2012 e janeiro e julho 2013, considerando o ambiente do reservatório de acordo com a resolução CONAMA № 357/2005.

\section{MATERIAL E MÉTODOS}

\section{Localização da área de estudo}

A presente pesquisa foi conduzida na área do reservatório da UHE Caçu (Figura 1), abrangendo as porções sul e sudeste do estado de Goiás, Brasil, entre os municípios de Cachoeira Alta e Caçu, na microrregião de Quirinópolis - GO. 


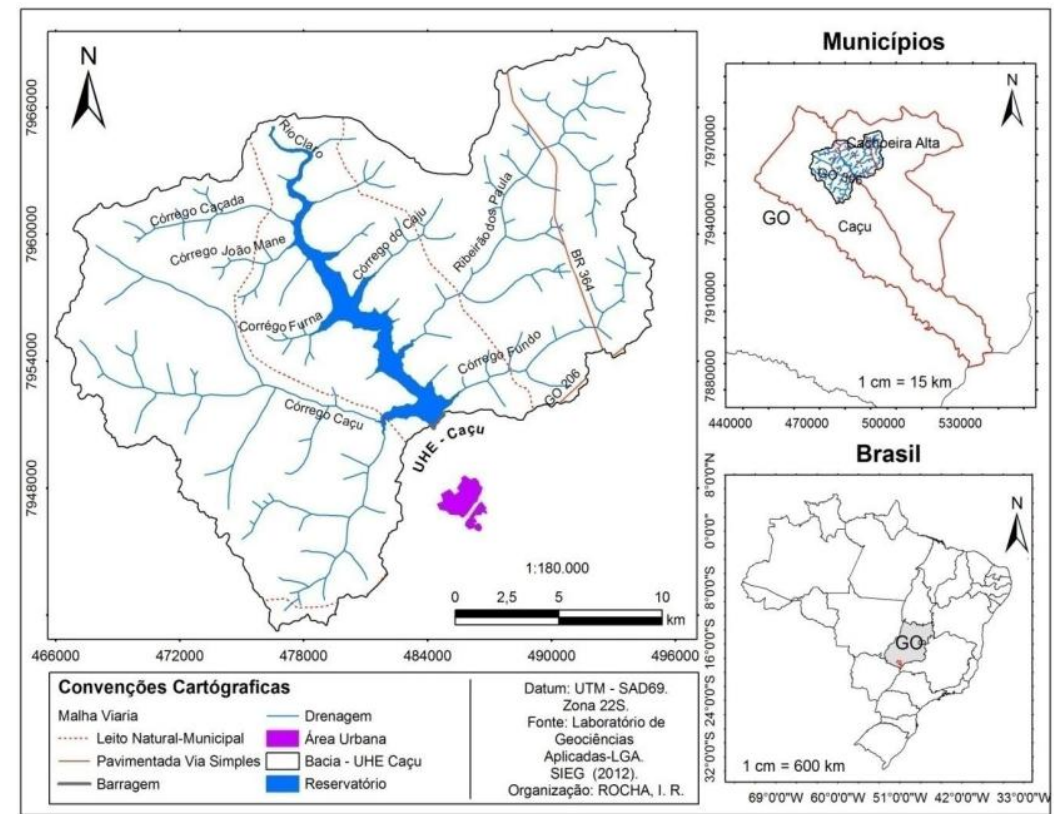

Figura 1: Localização da área da bacia hidrográfica da UHE Caçu. Fonte: Rocha, I. R. (2013).

\section{Caracterização Fisiográfica}

A descrição das características dos elementos dos sistemas da UHE Caçu é baseada em outras publicações, como da EMBRAPA (2009), nas contribuições de Guerra (1989), e em pesquisas recentes ocorridas na área em estudo.

A geologia da bacia da UHE Caçu compreende três formações geológicas: a Formação Vale do Rio do Peixe, predominante, a Formação Marília, em uma pequena parte na porção sul (Formações compõem o Grupo Bauru) e a Formação Serra Geral (Formação compõe o Grupo São Bento), que é encontrada no leito do rio Claro, nas drenagens da bacia.

Os levantamentos de solos apontam cinco tipos de solo: Latossolo Vermelho distrófico, Latossolo Vermelho perférrico, Argissolo Vermelho-Amarelo distrófico, Nitossolo Vermelho eutrófico e Neossolos Litólicos (EMBRAPA, 2009).

$\mathrm{Na}$ área de estudo, há presença de unidades topográficas bem distintas, nitidamente controladas pela litologia. A região é bem dissecada em vales bem amplos, limitadas por escarpas abruptas e sustentadas por afloramentos basálticos da Formação Serra Geral. As constituições geomorfológicas são: a Superfície Regional Aplainada IIIB, com cotas entre 550 e 750 m, associadas a relevos tabulares SRAIIIB - RT, e a SRAIIB-RT (m) - Superfície Regional Aplainada IIB com cotas entre 800 e 1000 m, associada a relevos tabulares, ocorre em uma pequena área (GUERRA, 1989; LATRUBESSE; CARVALHO, 2005). 
Na região, existem dois períodos distintos de distribuição das chuvas: um período menos chuvoso (chuvas até $80 \mathrm{~mm}$ ), com duração de 4 a 5 meses (maio a setembro) e, período chuvoso (outubro a abril). A área sofre efeito da massa Polar Continental, com desvio pluviométrico de até $20 \%$, sendo que a média anual de pluviosidade varia entre 1200 a 1600 milímetros (MARIANO; SANTOS; SCOPEL, 2003).

Na bacia da UHE Caçu, a vegetação é caracterizada pela presença de mata ciliar em parte do reservatório, áreas isoladas de cerradão e partes remanescentes de cerrado misturados à pastagem. As pastagens elevaram-se após a expansão e modernização da agricultura, em 1960, substituindo áreas de pastagens naturais por pastagens cultivadas (LIMA, 2013; PAULA et al., 2012).

\section{Definição de pontos de amostragens}

Para se compreender a distribuição espacial e temporal dos parâmetros limnológicos, foram definidos 35 pontos de amostragem no reservatório (Figura 2). Os pontos de amostragem foram definidos de modo a abranger todos os compartimentos aquáticos do reservatório (trecho rio, transição e lago), conforme a proposta de Kimmel et al. (1990). As coletas de dados foram realizadas nos dias 17/01/2012 e 23/01/2013 (Período chuvoso, pois ocorre um excedente hídrico na bacia), e nos dias menos chuvosos, em 10/07/2012 e 30/07/2013 (Período de estiagem, pois ocorre um déficit hídrico na bacia). 


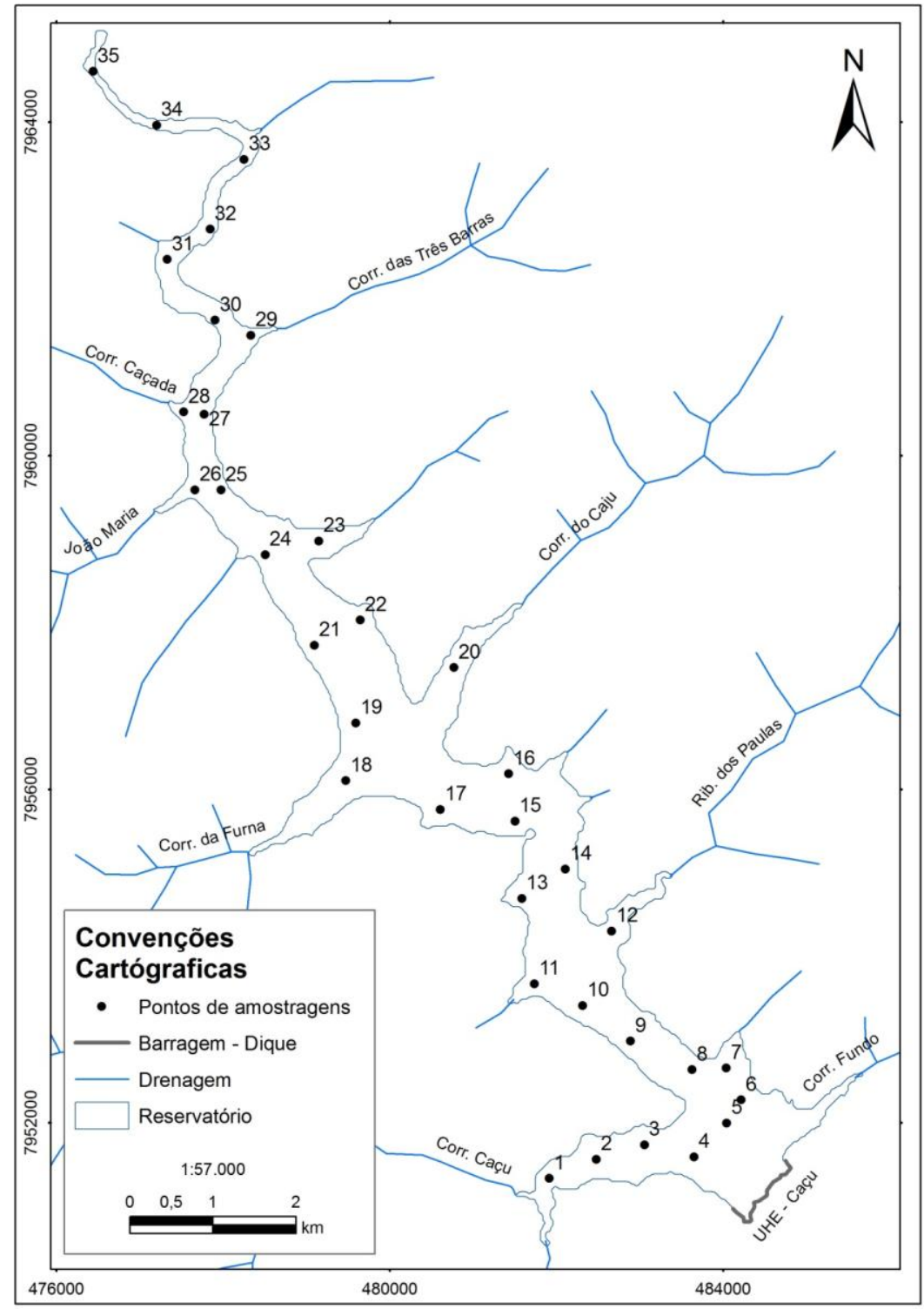

Figura 2: Pontos de amostragens de dados no reservatório da UHE Caçu. Fonte: Rocha, I. R. (2013).

\section{Variáveis limnológicas}

As variáveis limnológicas analisadas neste trabalho, conforme os objetivos são fundamentados em seis (06) parâmetros, sendo indicativos de qualidade da água como a condutividade elétrica $(\mu \mathrm{S} / \mathrm{cm})$, oxigênio dissolvido $(\mathrm{mg} / \mathrm{L}), \mathrm{pH}$ (Potencial Hidrogeniônico), temperatura da água (으), total de sólidos dissolvidos (mg/L) e Turbidez (UNT). Os parâmetros foram determinados, conforme estudos sobre caracterização de qualidade da água e dos corpos d'águas receptores indicados pela APHA (1995) e Von Sperling (1996).

Os padrões de qualidade e enquadramento dos corpos d'água foram definidos, de acordo com a Resolução CONAMA №357/2005, conforme descrito na Tabela 1. 


\begin{tabular}{|c|c|c|c|c|}
\hline $\begin{array}{c}\text { PARÂMETROS DE QUALIDADE } \\
\text { DA ÁGUA }\end{array}$ & $\begin{array}{c}\text { VALOR } \\
\text { MÁXIMO } \\
\text { (CLASSE 1) }\end{array}$ & $\begin{array}{c}\text { VALOR } \\
\text { MÁXIMO } \\
\text { (CLASSE 2) }\end{array}$ & $\begin{array}{c}\text { VALOR } \\
\text { MÁXIMO } \\
\text { (CLASSE 3) }\end{array}$ & $\begin{array}{c}\text { VALOR } \\
\text { MÁXIMO } \\
\text { (CLASSE 4) }\end{array}$ \\
\hline Condutividade elétrica (CE) & Sem padrão & Sem padrão & Sem padrão & Sem padrão \\
\hline Oxigênio Dissolvido (OD) & $\begin{array}{l}\text { Não inferior } \\
\text { a } 6 \mathrm{mg} / \mathrm{l}\end{array}$ & $\begin{array}{l}\text { Não inferior } \\
\text { a } 5 \mathrm{mg} / \mathrm{l}\end{array}$ & $\begin{array}{l}\text { Não inferior } \\
\text { a } 4 \mathrm{mg} / \mathrm{l}\end{array}$ & $\begin{array}{l}\text { Não inferior } \\
\text { a } 2 \mathrm{mg} / \mathrm{l}\end{array}$ \\
\hline Potencial Hidrogeniônico $(\mathrm{pH})$ & 6,0 a 9,0 & 6,0 a 9,0 & 6,0 a 9,0 & 6,0 a 9,0 \\
\hline Temperatura da água $\left({ }^{\circ} \mathrm{C}\right)$ & Sem padrão & Sem padrão & Sem padrão & Sem padrão \\
\hline $\begin{array}{l}\text { Total de sólidos dissolvidos } \\
\text { (TDS) }\end{array}$ & $500 \mathrm{mg} / \mathrm{l}$ & $500 \mathrm{mg} / \mathrm{l}$ & $500 \mathrm{mg} / \mathrm{l}$ & $500 \mathrm{mg} / \mathrm{l}$ \\
\hline Turbidez & Até 40 UNT & Até 100 UNT & Até 100 UNT & Até 100 UNT \\
\hline
\end{tabular}

Tabela 1: Padrões de qualidade da água das classes 1, 2, 3 e 4 de águas doces, segundo a Resolução CONAMA №357/2005.

Fonte: Resolução CONAMA 357/05.

\section{Análises das variáveis limnológicas}

As amostras de água foram coletadas conforme a proposta de Cabral et al.(2013), que compreende os primeiros $15 \mathrm{~cm}$ de profundidade, camada mais superficial do corpo d'água (epilímnio) onde tendem a ocorrer as maiores temperaturas, o que, juntamente com o aporte de nutrientes, aumenta a produtividade de organismos nas camadas superficiais. Assim, provoca o aumento de turbidez e diminuição da transparência, o que afeta a fotossíntese na coluna do corpo d'água.

Para as leituras das amostras de água utilizaram-se os equipamentos multiparâmentros, marca Oakton, modelo PCD650, e o Turbidímetro de bancada, modelo HI88703, marca Hanna. Os procedimentos de análise de água seguiram a descrição do Standard Methods for the Examination of Water and Wastewater (APHA, 1998).

Amostras de água foram coletadas com auxílio de um amostrador de material plástico transparente, com capacidade de 1 litro, para determinar em laboratório os índices de turbidez.

\section{Análise de correlação}

A correlação é a medida de dependência entre duas variáveis, servindo para medir o grau de associação entre elas. Assim, a pesquisa aplicou a proposta sugerida por Santos (2007), para discutir as medidas dos dados limnológicos analisados, por meio do coeficiente de correlação linear, que foram estabelecidos em relação aos intervalos de correlação, que podem variar entre +1 a -1 que se encontram na Tabela 2 . 


\begin{tabular}{|l|l|}
\hline \multicolumn{1}{|c|}{ COEFICIENTE } & \multicolumn{1}{c|}{ INTERVALOS } \\
\hline$r=1$ & Perfeita positiva - (PP) \\
\hline $0,7 \leq r<1$ & Forte positiva - (FtP) \\
\hline $0,4 \leq r<0,7$ & Moderada positiva - (MP) \\
\hline $0,1 \leq r<0,4$ & Fraca positiva - (FrP) \\
\hline $0<r<0,1$ & Ínfima positiva- (IP) \\
\hline 0 & Nula - (NL) \\
\hline$-0,1<r<0$ & Ínfima negativa - (IN) \\
\hline$-0,4<r \leq-0,1$ & Fraca negativa - (FrN) \\
\hline$-0,7<r \leq-0,4$ & Moderada negativa - (MN) \\
\hline$-1<r \leq-0,7$ & Forte negativa - (FtN) \\
\hline$r=-1$ & Perfeita negativa - (PN) \\
\hline
\end{tabular}

Tabela 2: Coeficiente de correlação linear e os intervalos de correlação. Fonte: Adaptado de Santos (2007).

\section{RESULTADOS E DISCUSSÃO}

\section{Análise Temporal das Variáveis Limnológicas}

Os dados limnológicos que são apresentados sequencialmente fazem parte dos resultados de dados coletados nas campanhas temporais no reservatório da UHE Caçu. As análises das águas e o enquadramento dos corpos d'água foram realizadas segundo as condições e padrões estabelecidos pela Resolução CONAMA n 357, de 17 de março de 2005.

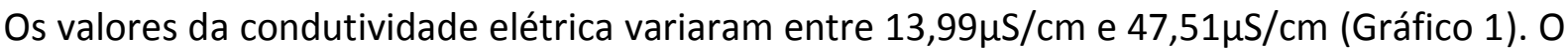
maior valor detectado encontra-se na área de influência do ponto de amostragem 19, que recebe as águas do córrego da Furna, trecho do reservatório que, conforme Cabral et al. (2013), pode ser considerada uma área intermediária ou de transição, conforme a proposta de Kimmel et al. (1990), ou seja, um trecho em que não se encontra lenta nem turbulenta a água.

Um dos fatores que pode ter elevado a concentração de CE no ponto 19 em relação aos demais pontos, é devido ao carreamento de sólidos para o reservatório, e a preparação do solo para plantio de vegetação nas áreas de APP (Foto 1). De acordo com os trabalhos de Coluna et al. (2007), Rocha Cabral e Braga (2014), com valores inferiores a $50 \mu \mathrm{S} / \mathrm{cm}$, e médio entre 50 e $100 \mu \mathrm{S} / \mathrm{cm}$, sendo um indicativo de que a região é formada por rochas fracas e não resistentes ao intemperismo, que são ricas em material carbonário, aumentando a condutividade após a dissolução. 


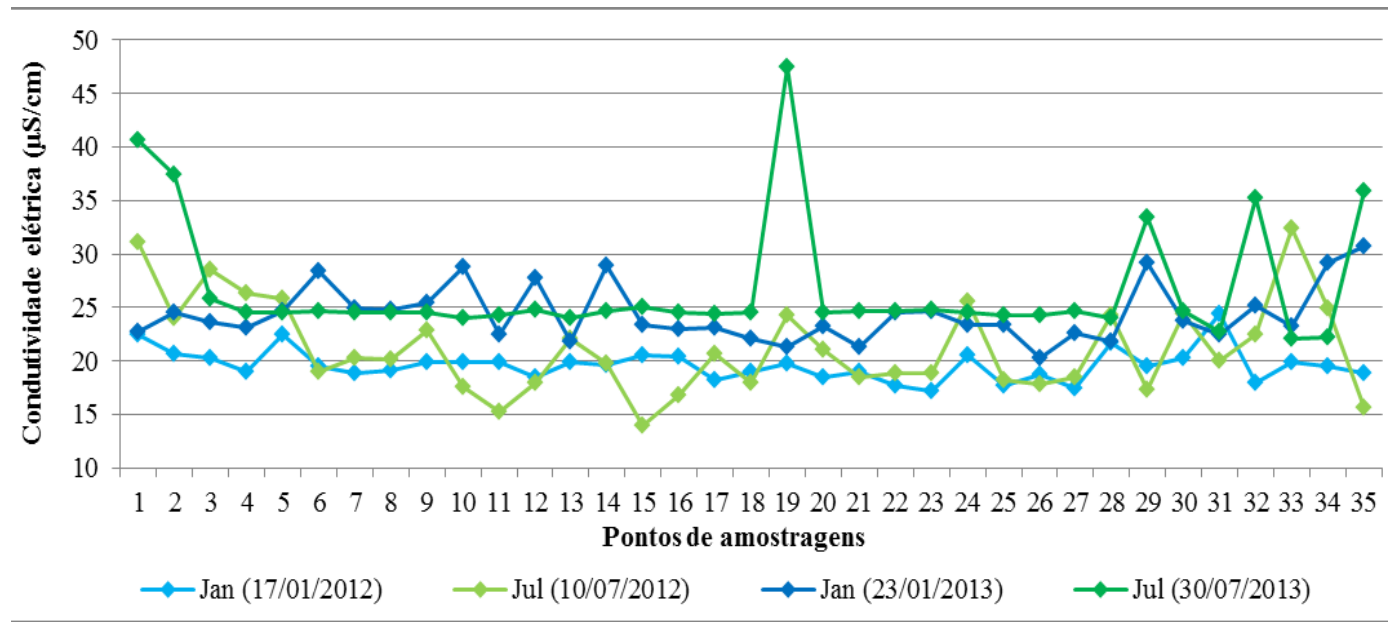

Gráfico 01: Variação temporal e espacial da condutividade elétrica das águas do reservatório da UHE Caçu. Fonte: Rocha, I. R. (2013).

Os valores de CE detectados na UHE Caçu podem ser considerados baixos, sendo um indicativo de que a litologia da região pode identificar a qualidade das águas. O lago da UHE Caçu foi constituído sobre as rochas basálticas da Formação Serra Geral, o que poderia resultar em água rica em carbonatos de cálcio $(\mathrm{CaCO} 3)$ e, após a dissolução das rochas da Formação Vale do Rio do Peixe e Marília, que são ricas em materiais carbonatos, são carreadas para o reservatório através dos afluentes.

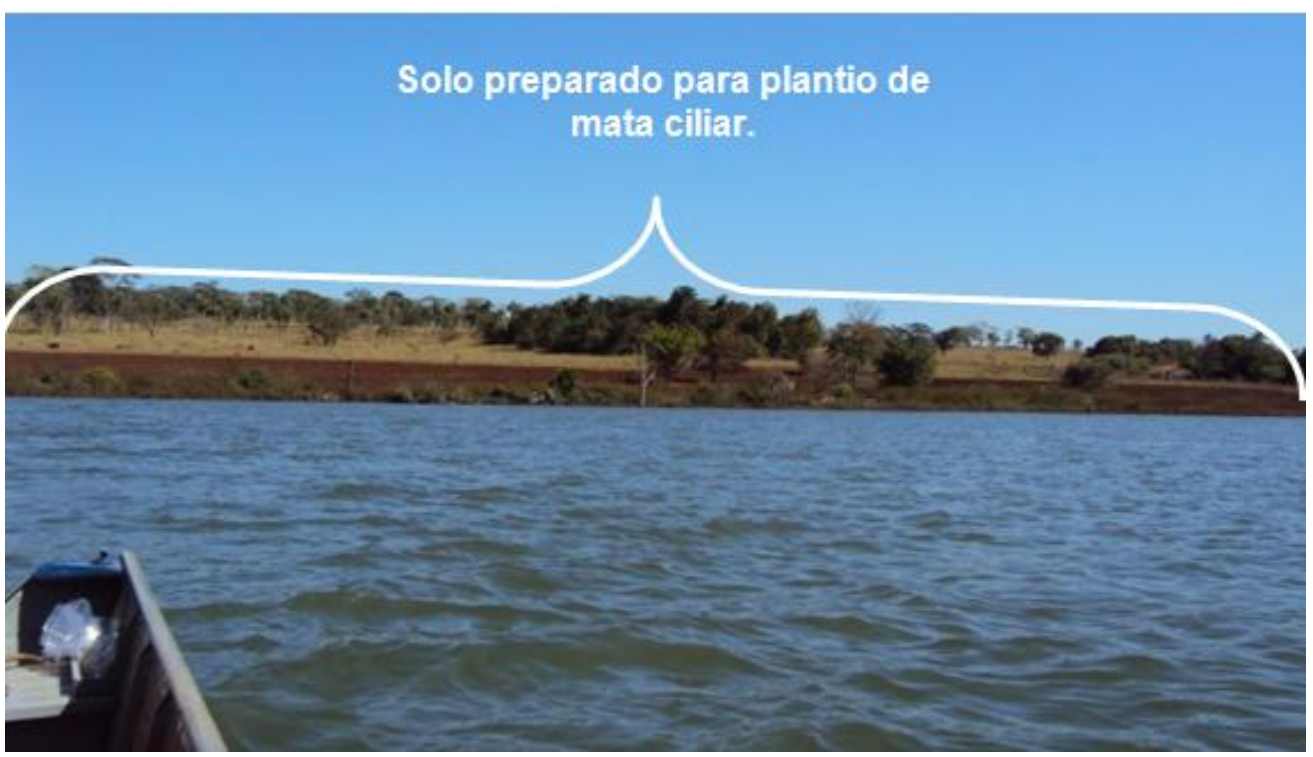

Figura 3: Paisagem próxima do ponto de amostragem 19, margem direita do reservatório da UHE Caçu e o solo exposto, devido ao preparo para plantio de mata ciliar.

De acordo com as análises realizadas, O OD apresentou valores que podem ser classificados em todas as classes de águas doces previstas pela resolução CONAMA. O valor mínimo obtido foi de $0,2 \mathrm{mg} / \mathrm{L}$, e o máximo de $10 \mathrm{mg} / \mathrm{L}$ (Gráfico 2). No período chuvoso de 2013 , 
obtiveram-se índices inferiores a $2 \mathrm{mg} / \mathrm{L}$ que classificaram o corpo d'água do reservatório como de classe 4.

Os baixos valores verificados para OD na campanha de janeiro de 2013 podem ser associados ao período de estiagem naquele ano, pois, no período de poucas chuvas, o tempo de residência do oxigênio na água é de até 16 dias (NOVELIS, 2005).

As oscilações de OD em relação aos períodos observados, principalmente o período de chuva de 2013, podem ser as responsáveis por uma série de problemas na qualidade da água, e também aos que afetam a biota aquática, diretamente na respiração dos microorganismos (VON SPERLING, 1996), pois, o oxigênio dissolvido é essencial para a sobrevivência dos ecossistemas aquáticos. Conforme a resolução CONAMA no 357/05, as amostras não podem conter valores inferiores a $6 \mathrm{mg} / \mathrm{L}$ para a classe $1 ; 5 \mathrm{mg} / \mathrm{L}$ na classe 2; $4 \mathrm{mg} / \mathrm{L}$ na classe 3; $2 \mathrm{mg} / \mathrm{L}$ na classe 4.

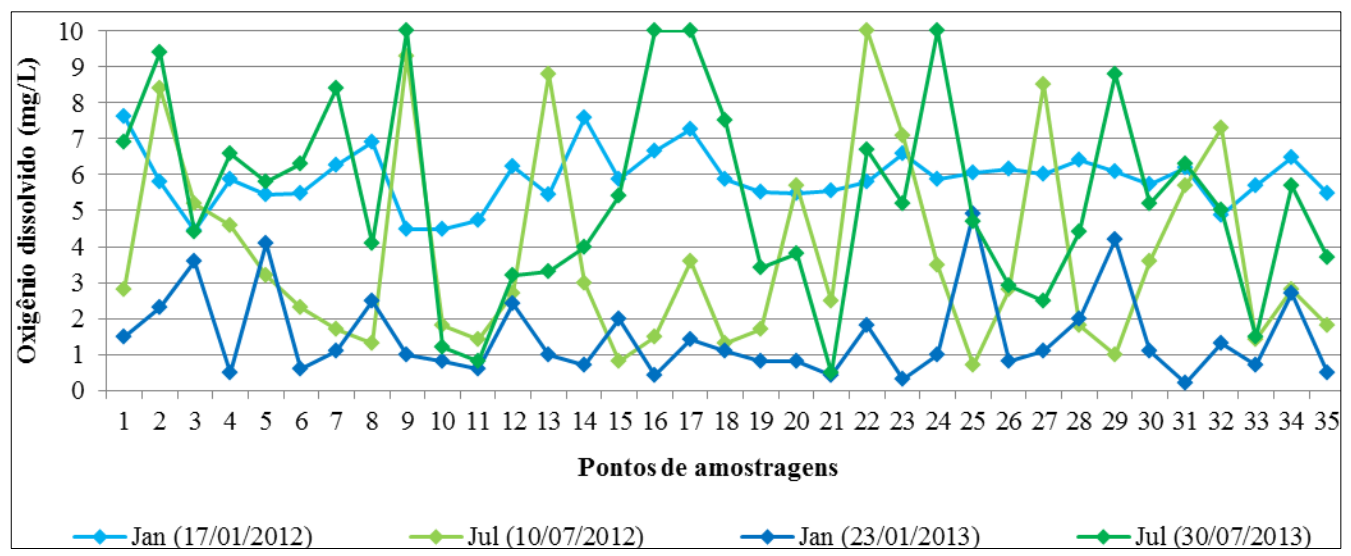

Gráfico 02: Variação temporal e espacial do Oxigênio Dissolvido do reservatório da UHE Caçu. Fonte: Rocha, I. R. (2013).

Segundo a CETESB (2013) e Esteves (1998), o aumento da temperatura intensifica a produção fitoplanctônica, aumentando a absorção de nutrientes por esses organismos. Assim, a solubilidade do oxigênio na água diminui e aumenta a solubilidade de vários compostos químicos que afetam a vida aquática. Durante a decomposição da matéria orgânica, pode ocorrer, ainda, uma diminuição da concentração de oxigênio dissolvido na água, principalmente em reservatórios de grandes profundidades.

Em relação ao pH (Gráfico 3), o mesmo se encontra dentro dos padrões estabelecidos pela Resolução CONAMA no 357/05, que indica pH de 6 a 9 para todas as classes de águas doces. Conforme Kleerekoper (1990), o pH abaixo de 6 e acima de 9 é raro, mas, em pesquisas 
realizados por Kleerekoper, para os açudes do nordeste brasileiro apresentaram valor de $\mathrm{pH}$, em sua maioria, acima de 8,0. Abaixo de 7,7, trata-se de uma reação ácida, e, acima desse valor, reação alcalina, o que caracteriza que as águas do reservatório de Caçu estão com seus valores em torno da média estipulada pelo CONAMA.

As variações no $\mathrm{pH}$ podem ter sido modificados por outras variáveis liminológicas, ou modificou-as e vice-versa, aumentando ou diminuindo o pH. Observou-se, neste estudo, uma tendência de elevação do pH no período de chuva de 2012 e período de seca de 2013.

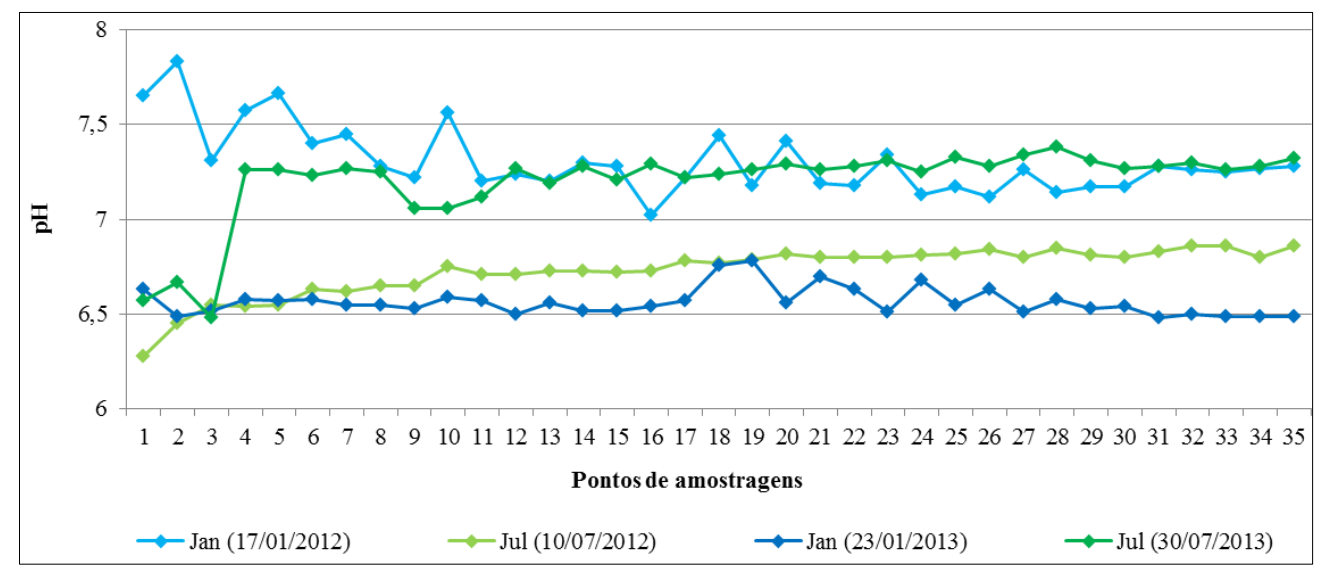

Gráfico 03: Variação temporal e espacial do pH do reservatório da UHE Caçu. Fonte: Rocha, I. R. (2013).

Segundo Esteves (1988), muitos fatores, como a geologia do local, contribuem para a variação do pH em ecossistemas aquáticos. O ambiente geológico condicionou os valores de $\mathrm{pH}$ que foram obtidos nas campanhas, pois o mínimo foi de 6,28 e o máximo 7,83, apresentando distribuição, devido ao fato de o ambiente ser composto por rochas basálticas da Formação Serra Geral.

Morais e Silva (2012), ao estudarem as águas do rio Poti, no Piauí, verificaram que a ocorrência de precipitação pluvial resultava na redução no pH da água, fato este semelhante aos que ocorreram para o reservatório de Caçu, quando se comparam os dados de $\mathrm{pH}$, nos anos de 2012 e 2013. Segundo os autores, esse cenário pode ter como causa a poluição por ureia e compostos químicos originados das áreas de pecuária e agricultura, fato este que também ocorre nas áreas próximas ao reservatório de Caçu, embora outros fatores pudessem ter atuado em conjunto, como a dissolução de rochas, absorção de gases da atmosfera, oxidação da matéria orgânica e atividade fotossintética, dentre outros, conforme Von Sperling (1996). 
A temperatura relaciona-se com muitas variáveis. Os resultados obtidos para temperatura superficial da água apresentaram-se bastante uniformes em toda a extensão do reservatório. Este é um parâmetro de grande importância para a comunidade aquática, já que influencia a maioria dos processos físicos, químicos e biológicos na coluna d'água (ESTEVES, 1998).

As temperaturas da água nos dias das coletas apresentaram valores de mínima 17,64 ㅇ $\mathrm{C}$ máxima 34,40드 (Gráfico 4). Os meses de janeiro são característicos de altas temperaturas, porém, se o ambiente estiver nublado e chuvoso, a temperatura da água tende a diminuir, episódio que ocorreu em janeiro de 2012, em que a temperatura esteve baixa durante todas as amostragens no reservatório. Em julho, houve homogeneidade nos valores analisados e as variações foram baixas, tanto no ano de 2012, como em 2013.

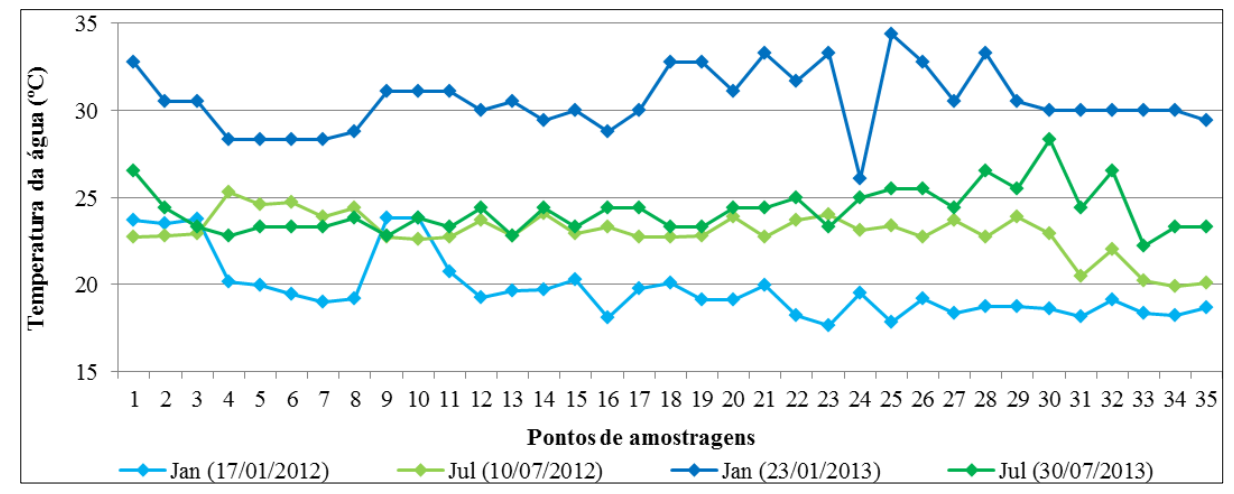

Gráfico 04: Variação temporal e espacial da Temperatura do reservatório da UHE Caçu. Fonte: Rocha, I. R. (2013).

Segundo o EIA/RIMA da UHE Caçu e Barra dos Coqueiros (NOVELIS, 2005), o clima da área de estudo, nos meses chuvosos, sofre influência das massas de ar provenientes da Amazônia e do Chaco, que atuam no sudoeste goiano, em que se registram valores mais altos de umidade relativa do ar de 68 a 85\%, em média. Nos meses mais secos, são registrados os valores mais baixos de umidade relativa do ar, entre 46 a $69 \%$, e as temperaturas médias do ar variam pouco entre as estações do ano, com médias entre 22 a $22,5^{\circ} \mathrm{C}$.

Segundo Rocha, Cabral e Braga (2014), na Bacia da UHE Barra dos Coqueiros, as temperaturas da água nos afluentes apresentaram uma média entre 22,6 a $24,6^{\circ} \mathrm{C}$, enquanto que nos afluentes da UHE Caçu foram de 21,3 a $23,1^{\circ} \mathrm{C}$ (BARCELOS et al., 2012). Assim, os índices de temperatura da água são fundamentais para alterações na biota aquática, bem como para a produção de oxigênio, decomposição da matéria orgânica e outras reações. 
Arcova et al. (1998), ao estudarem bacias hidrográficas na mata atlântica, detectaram valores de temperatura da água nos rios do Município de Cunha, Estado de São Paulo, abaixo de $20{ }^{\circ} \mathrm{C}$, pois a vegetação que acompanha a zona ripária dessas microbacias proporcionava efetiva proteção contra o aquecimento excessivo da água, mas as temperaturas médias estiveram sempre acima de 21 으, fenômeno típico da capacidade de retenção de calor de massas d'água represadas.

No estudo realizado por Almeida e Schwarzbold (2003), a variação de temperatura da água do arroio Cria Montenegro (RS) ocorreu, principalmente, em relação aos diferentes volumes de água e à falta de cobertura vegetal florestal ao longo do percurso do rio, que servissem de anteparo para os raios solares, fato esse que pode também ser associado ao reservatório de Caçu, devido à falta de vegetação nas margens.

As concentrações de TDS, podem ter sido influenciados por outras variáveis, como a condutividade elétrica e o pH. Os valores de TDS assemelham-se na distribuição com a variável $\mathrm{CE}$, devido à quantidade de íons em solução dissolvidos no momento das análises, que alteraram os resultados de $\mathrm{CE}$ e $\mathrm{pH}$.

Os valores de TDS apresentaram maior concentração $(22,8 \mathrm{mg} / \mathrm{L})$ no ponto de amostragem 19. O resultados ficaram entre 7 a $20,8 \mathrm{mg} / \mathrm{L}$ (Gráfico 5).

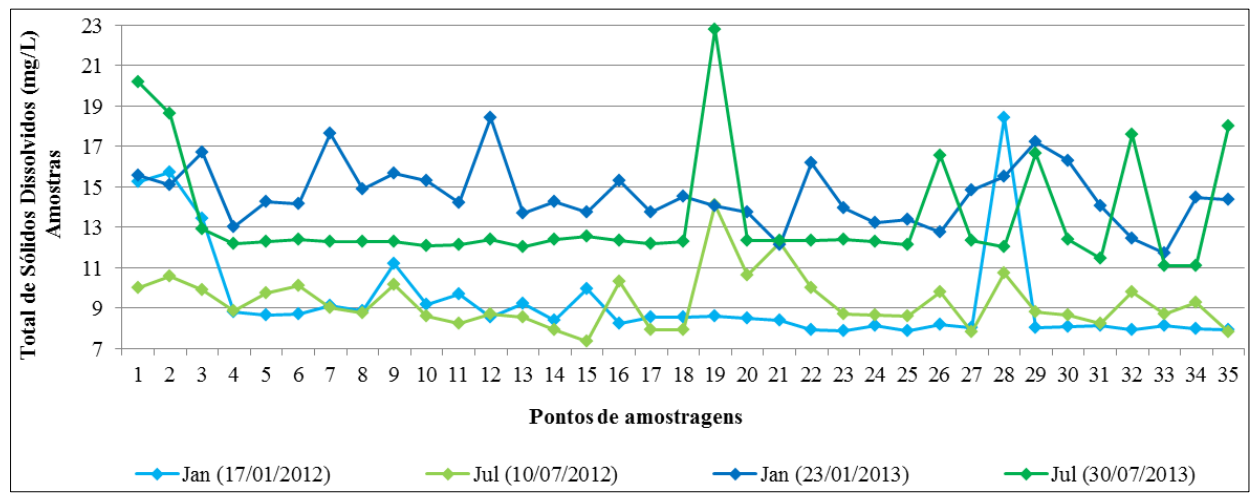

Gráfico 05: Variação temporal e espacial do Total de Sólidos Dissolvidos do reservatório da UHE Caçu. Fonte: Rocha, I. R. (2013).

A diferença de valores do TDS entre os anos de 2012 e 2013, podem ser associados a decomposição da vegetação submersa, pois a mesma pode ter elevado a concentração de íons na água, fato este que pode ser associado às concentrações de pH (Gráfico 3).

Os valores identificados por Rocha, Cabral e Braga (2014) obtiveram níveis de total de sólidos dissolvidos na água de 10 a $15 \mathrm{mg} / \mathrm{L}$ nos afluentes da bacia hidrográfica da UHE Barra 
dos coqueiros, no período chuvoso, enquanto que, no período seco, os índices foram de 5 a $10 \mathrm{mg} / \mathrm{L}$, assemelhando-se aos resultados obtidos nessas análises.

Os PA 1, 2 e 3 são os primeiros pontos de coleta e registraram, sempre, maiores valores para o TDS. Esse fator pode ser associado ao fato de estarem localizados próximos da entrada do afluente córrego Caçu (maior microbacia afluente do reservatório da UHE Caçu) e de uma ponte e área de lazer, o que ocasiona prováveis exposições à entrada de poluentes (Foto 2 ).

Esses pontos também se encontram próximos às áreas agrícolas, que, possivelmente, proporcionarão uma concentração de sedimentos orgânicos e inorgânicos ao sistema em análise. De acordo com a Resolução CONAMA no 357/2005, que determina o padrão de potabilidade da água destinada ao consumo humano, a concentração de sólidos dissolvidos total deve ficar abaixo de $500 \mathrm{mg} / \mathrm{L}$, para corpos de água.

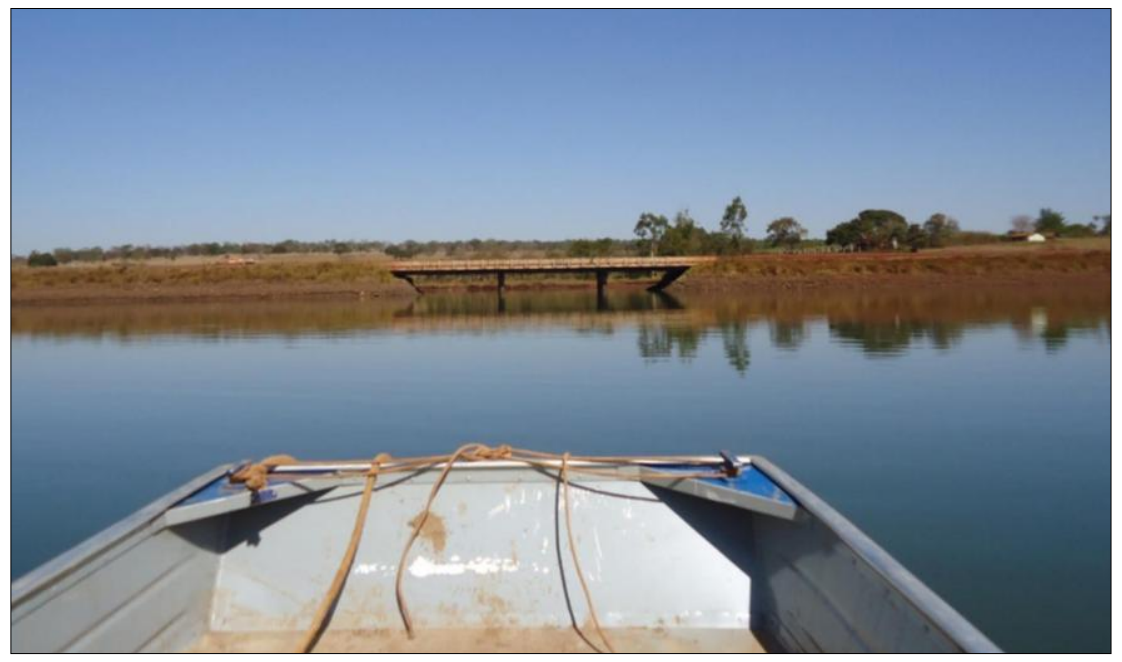

Figura 4: Paisagem próxima do PA 1, 2 e 3, afluente do reservatório da UHE Caçu.

Os níveis de TDS analisados por Awomeso et al. (2010) para região de Ikorodu, Nigéria, ficaram entre 673-45.216 mg/L, e a OMS (1998) tem recomendado níveis de TDS de 500 $\mathrm{mg} / \mathrm{L}$ a $2000 \mathrm{mg} / \mathrm{L}$, respectivamente, em água potável. Já o padrão brasileiro do CONAMA (2005) é de até $500 \mathrm{mg} / \mathrm{L}$ para todas as classes de águas doces. O TDS na região de Ikorodu esteve na maior parte acima dos valores da OMS, e pode estar associado à presença de uma gama de contaminantes químicos.

No rio Bebar, Gasim et al. (2007), encontraram nas amostras de água coletadas valores variando de 57 a $120 \mathrm{mg} / \mathrm{L}$ de TDS. Enquanto que a turbidez variou de 1,5 a 17,15 UNT. 
Comparativamente, o valor de turvação ficou dentro das normas internacionais da OMS, assim como o TDS.

A turbidez está fortemente relacionada com as erosões causadas pelo destino do uso da terra, como áreas de pastagens degradadas, descobertas de vegetação, preparadas para plantio agrícola, que provocam transportes, em grandes quantidades, de sedimentos. Assim, a turbidez aumenta após chuvas fortes, carreando sedimentos das margens e também pelas enxurradas.

As campanhas registraram altos valores de turbidez, para os pontos de amostragem próximos à montante do reservatório, que ainda se assemelha a fase de rio. Mas, os dados ficaram nos limites do padrão determinado pelo CONAMA no 357/05, e também ultrapassaram os mesmos, apresentando índices acima de 100UNT, com o maior valor registrado de 157UNT no período chuvoso (Gráfico 6). Os pontos amostrados com elevada Turbidez estão localizados nas saídas de afluentes, próximos ao trecho de rio do reservatório.

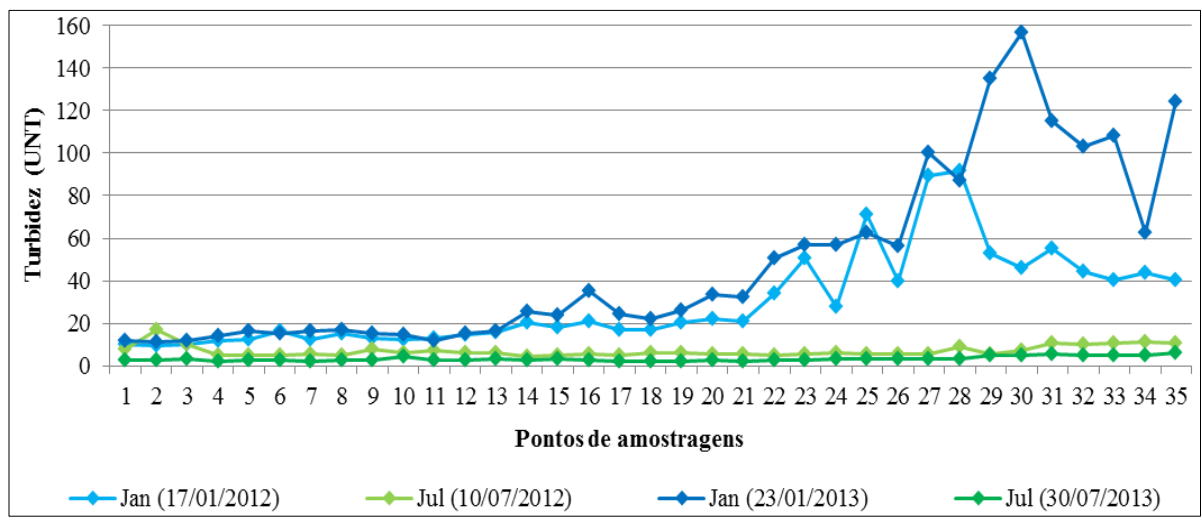

Gráfico 06: Variação temporal e espacial da Turbidez do reservatório da UHE Caçu. Fonte: Rocha, I. R. (2013).

$\mathrm{Na}$ época de estiagem das chuvas, a concentração da turbidez sempre tem índices baixos nessa área em estudo (UHE Caçu). Assim, foram registrados, em todos os pontos, valores de turbidez abaixo de 40UNT.

De acordo com Esteves (1998), um exemplo referente ao aumento da turbidez em ambientes rasos (até mais ou menos 3,0 $\mathrm{m}$ de profundidade), os peixes reduzem a biomassa vegetal tanto por digestão, como provocando o revolvimento do sedimento. Assim, este processo leva a uma significativa redução da taxa de produtividade primária, através da redução da penetração de luz. 


\section{Análises estatísticas}

A avaliação por meio da correlação linear de Pearson foi aplicada na tentativa de responder o quanto as variáveis limnológicas possuíam relação entre si. A análise foi efetuada utilizando os dados provenientes das campanhas dos campos do ano de 2012 e 2013, de acordo com a proposta, adaptada de Santos (2007).

Na discussão dos dados do reservatório de Caçu, foram utilizadas as correlações médias e altas obtidas através das variáveis limnológicas, sendo discutidos somente os valores acima de 0,4 (positiva ou negativa) de correlação, ou seja, que se encaixem no coeficiente de correlação > 0,4; acima desse nível, que é considerada "Moderada positiva - (MP)", ou >-0,4 “Moderada negativa - (MN)", segundo a proposta adaptada de Santos (2007).

Assim, as correlações "Fraca positiva - (FrP)", "Fraca negativa - (FrN)", "Ínfima positiva (IP)" e "Ínfima negativa (IN)" ou "Nula (NL)" não serão abordadas nas discussões dos gráficos, por se tratar de valores baixos para demonstração nos gráficos de dispersões, embora estatisticamente possuam valores expressivos segundo as análises dos dados.

Os valores de correlação existentes entre as variáveis estudadas e os valores expressivos superiores 0,4 encontram-se tarjados de vermelho e são apresentados na Tabela 3.

Entre os dados analisados, os maiores valores de correlações ocorreram entre as variáveis CExpH, CExTDS, pHxT, pHxTDS, TxTDS e TxTUR, e consequentemente no período chuvoso de 2012.

A CE apresentou correlação com o TDS, no período chuvoso de 2012 e período de estiagem de 2013. Demostrando que, quanto maior a concentração de sólidos em suspensão, maior será a capacidade de CE na água.

A CE demonstra relação com a temperatura, no período chuvoso de 2012 , a temperatura baixa (média de 19ํ) contribuiu para a retenção da condutividade, que é observada pelos baixos valores registrados nessa campanha de 2012, com média de 19,65 $\mathrm{S} / \mathrm{cm}$, comparados aos do mês de janeiro de 2013, com média de $24,41 \mu \mathrm{S} / \mathrm{cm}$, em que a temperatura esteve com média de 30 으.

\begin{tabular}{|l|r|r|r|r|r|r|r|r|}
\hline \multicolumn{1}{|c|}{ VARIÁVEIS } & \multicolumn{2}{|c|}{ PC (17/01/2012) } & \multicolumn{2}{|c|}{ PE (10/07/2012) } & \multicolumn{2}{|c|}{ PC (23/01/2013) } & \multicolumn{2}{|c|}{ PE (30/07/2013) } \\
\hline CEXOD & 0,05 & IP & 0,15 & FrP & 0,18 & FrP & 0,09 & IP \\
\hline CExpH & 0,24 & FrP & $-0,34$ & FrN & $-0,45$ & MN & $-0,33$ & FrN \\
\hline CExT & 0,30 & FrP & $-0,15$ & FrN & $-0,36$ & FrN & 0,18 & FrP \\
\hline
\end{tabular}




\begin{tabular}{|l|r|r|r|r|r|r|r|r|}
\hline CExTDS & 0,45 & MP & 0,29 & FrP & 0,36 & FrP & 0,96 & FtP \\
\hline CExTUR & $-0,12$ & FrN & 0,37 & FrP & 0,13 & FrP & 0,06 & IP \\
\hline ODxpH & $-0,23$ & FrN & $-0,15$ & FrN & $-0,18$ & FrN & $-0,13$ & FrN \\
\hline ODxT & $-0,34$ & FrN & 0,07 & IP & 0,09 & IP & 0,10 & IP \\
\hline ODxTDS & 0,03 & IP & 0,07 & IP & 0,34 & FrP & 0,06 & IP \\
\hline ODxTUR & 0,15 & FrP & 0,23 & IP & 0,00 & NL & $-0,17$ & FrN \\
\hline pHxT & 0,74 & FtP & 0,20 & FrP & 0,31 & FrP & 0,03 & IP \\
\hline pHxTDS & 0,52 & MP & $-0,14$ & FrN & $-0,18$ & FrN & $-0,32$ & FrN \\
\hline pHxTUR & $-0,34$ & FrN & $-0,39$ & IN & $-0,31$ & FrN & 0,13 & FrP \\
\hline TxTDS & 0,57 & MP & 0,08 & IP & $-0,08$ & IN & 0,24 & FrP \\
\hline TxTUR & $-0,58$ & MN & $-0,65$ & FtN & 0,02 & IP & 0,23 & FrP \\
\hline TDSxTUR & $-0,01$ & IN & 0,09 & IP & $-0,06$ & IN & 0,08 & IP \\
\hline
\end{tabular}

\begin{tabular}{|r|l|}
\hline \multicolumn{2}{|c|}{ LEGENDA } \\
\hline CE & Condutividade Elétrica \\
\hline FrN & Fraca negativa \\
\hline FtN & Fraca positiva \\
\hline FtP & Forte negativa \\
\hline IN & Ínfima negativa \\
\hline IP & Ínfima positiva \\
\hline MN & Moderada negativa \\
\hline MP & Moderada positiva \\
\hline NL & Nula \\
\hline OD & Oxigênio Dissolvido \\
\hline PH & Potencial Hidrogeniônico \\
\hline PN & Perfeita negativa \\
\hline PP & Perfeita positiva \\
\hline T & Temperatura da Água \\
\hline TDS & Total de Sólidos Dissolvidos \\
\hline TUR & Turbidez \\
\hline & Valores de "r" significativos estão em vermelho. \\
\hline
\end{tabular}

Tabela 3: Matriz das correlações e intervalos para o Período Chuvoso (PC) e Período de Estiagem (PE). Fonte: Rocha, I. R. (2013), baseado de Santos (2007).

No período chuvoso de 2013, a temperatura alta proporcionou a maior dissolução dos íons de H+. Segundo Wetzel (1983) e Esteves (1998), à medida que o pH e a temperatura aumentam, modificam-se os valores de condutividade. Logo, em julho de 2013, as variáveis CE e TDS obtiveram maior valor de correlação $r=0,96$ (FtP), índice satisfatório para as duas variáveis.

$\mathrm{O}$ pH se relacionou com a $\mathrm{T}(r=0,74)$ e com TDS $(r=0,52)$, indicando que, no período chuvoso de 2012, essas variáveis tiveram seus dados correspondentes.

A temperatura é uma variável importante, como já expresso muitas vezes nesse trabalho, e se relacionou com o TDS $(r=0,57)$. A temperatura com a turbidez correlacionou-se em janeiro de 2012, com $r=-0,58$, e do mesmo modo no julho de 2012 (MN), com $r=-0,65$. 
A CE e o TDS (Gráfico 7 e 8), apresentaram em janeiro de 2012, e julho de 2013, correlações positivas. Em janeiro apenas $20 \%$ dos dados estão ajustados à linha de tendência. 0 coeficiente de determinação linear $\left(r^{2}\right)$ entre a CE e o TDS, em julho de 2013, indicou cerca de $93 \%$ dos dados ajustados à linha de tendência.

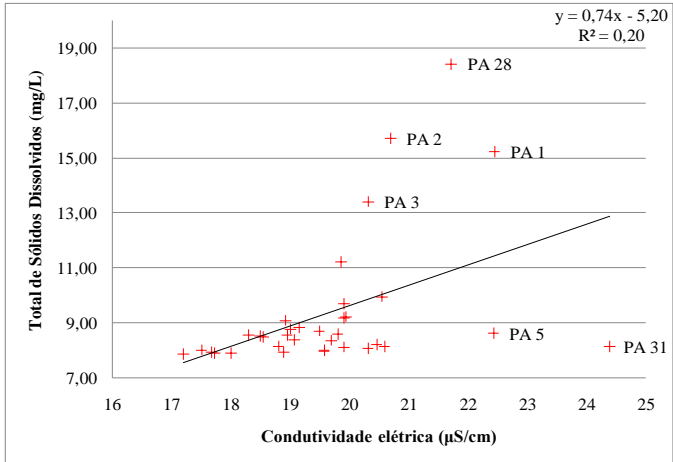

Gráfico 7: Diagrama de dispersão entre CE e TDS de janeiro de 2012.

Fonte: Rocha, I. R. (2013).

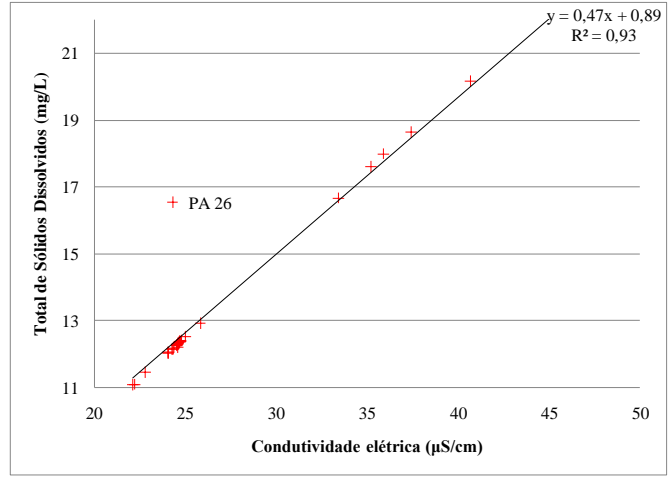

Gráfico 8: Diagrama de dispersão entre CE e TDS de julho de 2013.

Fonte: Rocha, I. R. (2013).

A correlação desses parâmetros está associada diretamente com a quantidade de sal na água, sendo que a intensificação dos valores desses parâmetros é ocasionada devido à cristalização dos minerais, aumentando a concentração de íons no meio aquático (ALVES, 2009).

A CE e o pH (Gráfico 9) apresentaram, em janeiro de 2013, correlação negativa, ajustando somente $20 \%$ dos dados à linha de tendência, o que comprova grande dispersão dos dados, sendo que, quanto maiores forem os valores de $\mathrm{pH}$, menor é a capacidade da água em transportar energia elétrica.

Percebe-se que o coeficiente que melhor se ajustou à linha de tendência do $\mathrm{pH}$ foi a temperatura, com 55\% de associação (Gráfico 10). A temperatura e o pH se assemelham, reação causada pela concentração de íons que se eleva com a temperatura (ESTEVES, 1998).
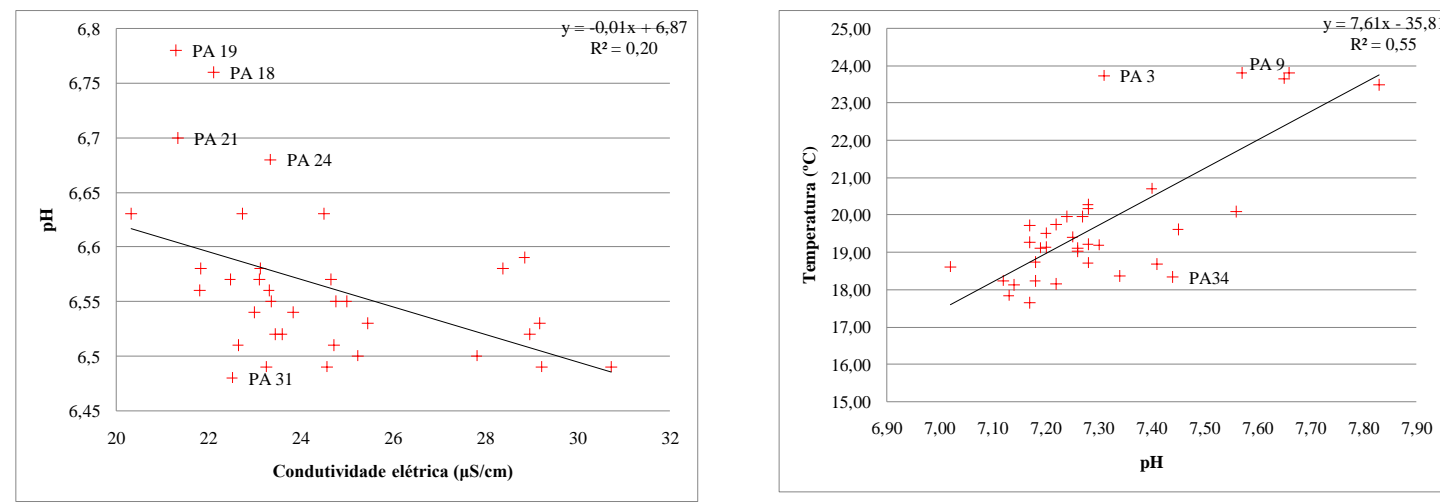
Gráfico 9: Diagrama de dispersão entre CE e pH de janeiro de 2013. Fonte: Rocha, I. R. (2013).
Gráfico 10: Diagrama de dispersão entre as variáveis pH e T de janeiro de 2012.

Fonte: Rocha, I. R. (2013).

O pH e o TDS (Gráfico 11) seguiram a mesma tendência, pois são influenciados pela concentração de íons dissolvidos na água. O coeficiente linear $\left(r^{2}\right)$ foi de $27 \%$ de similaridade dos dados. Alguns pontos ficam distantes da reta (pontos 1, 2, 13 e 28). Como visto anteriormente nos resultados apresentados, esses pontos tiveram diferenças nos dados, sempre com valores mais elevados que os demais na maior parte das variáveis.

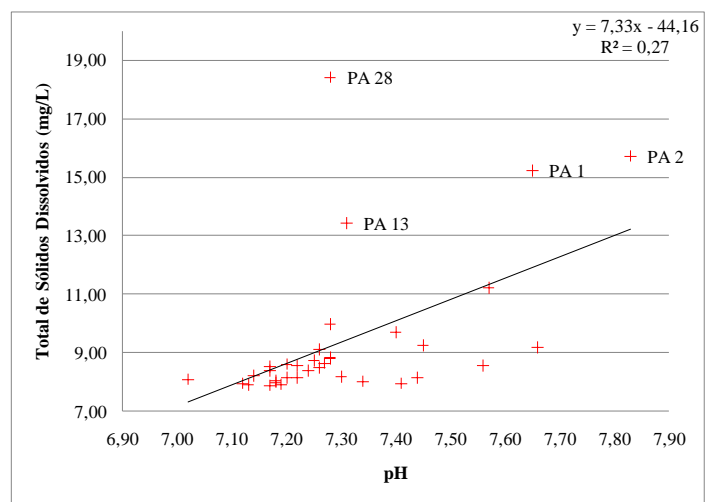

Gráfico 11: Diagrama de dispersão entre as variáveis pH e TDS de janeiro de 2012.

Fonte: Rocha, I. R. (2013).

Segundo Rocha, Cabral e Braga (2014), que também obtiveram melhor resposta entre as variáveis $\mathrm{pH}$ e temperatura da água nos afluentes da bacia da UHE Barra dos Coqueiros, sendo essas variáveis com respostas de relações positiva e negativa, demonstrando que, quanto menor a temperatura, maior os valores de $\mathrm{pH}$, e inversamente em outros períodos.

Conforme os Gráficos 12 e 13, de dispersões entre as variáveis T e turbidez, verifica-se que em janeiro de 2012 apresentou 33\% dos dados correlacionados, e, no mesmo ano, em julho, correspondendo a $42 \%$ dos eventos. Os pontos mantêm-se próximos da linha de regressão, embora alguns agrupados. As diferenças entre os gráficos dão-se pelos valores de turbidez, que se apresentam mais elevados em janeiro. O coeficiente de correlação de julho de 2012 foi mais significativo, pois, nesse período, os dados apresentam-se padronizados para essas variáveis; apenas no ponto 2 observou-se 17,10 UNT, valor acima dos demais pontos, que confere por estar próximo da entrada de um afluente, o córrego Caçu, que possui uma ponte e área de lazer nas mediações, e estar exposto a prováveis entradas de sedimentos e poluentes. 
Os valores de T e TDS apresentaram 33\% dos dados relacionados entre si no período chuvoso de 2012 (Gráfico 14). As variações na distribuição dos dados não foram igualmente obtidas pela T e nem pelo TDS, porque alguns pontos (pontos de amostragens 1, 2, 9, 10, 13 e 28) ficaram fora do padrão. Assim, as altas temperaturas não combinaram com os valores de TDS, e, ao contrário, no ponto 28 , o valor de TDS esteve acima dos outros registros de TDS durante esse período.

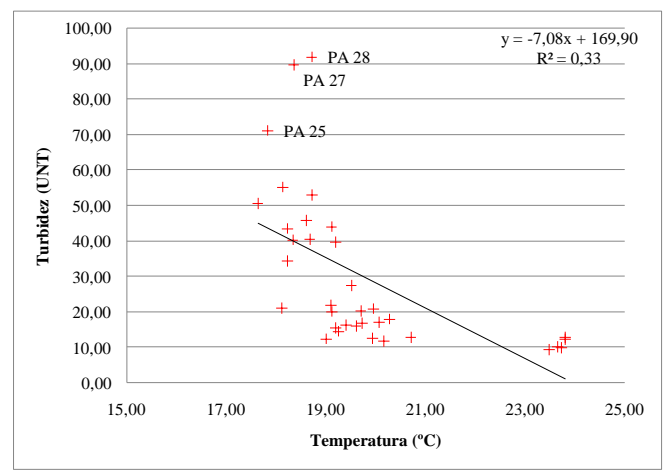

Gráfico 12: Diagrama de dispersão entre as variáveis T e Turbidez de janeiro de 2012. Fonte: Rocha, I. R. (2013).

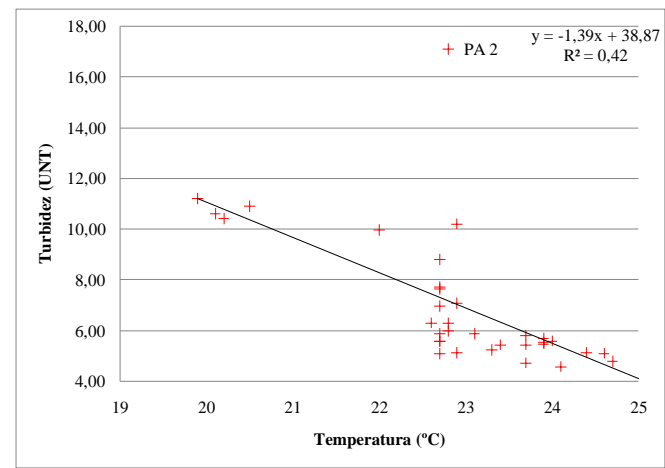

Gráfico 13: Diagrama de dispersão entre as variáveis T e Turbidez de julho de 2012. Fonte: Rocha, I. R. (2013).

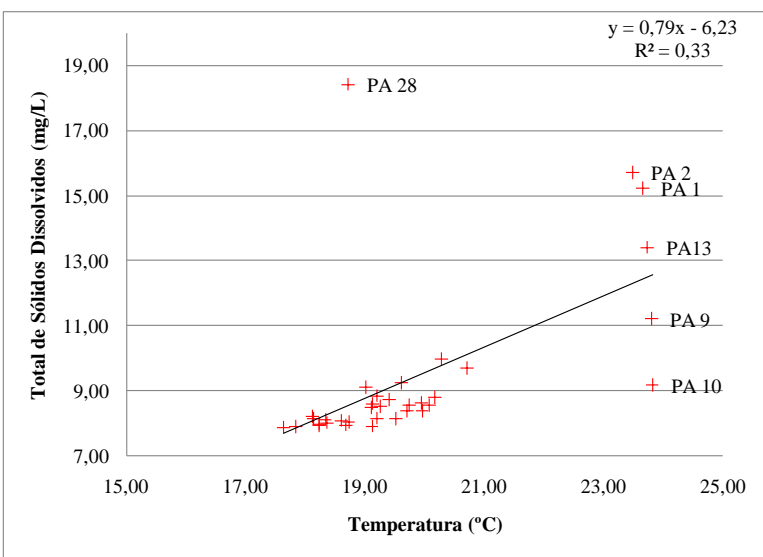

Gráfico 14: Diagrama de dispersão entre as variáveis T e TDS de janeiro de 2012. Fonte: Rocha, I. R. (2013).

\section{CONCLUSÃO}

As variáveis analisadas estão intimamente relacionadas ao ambiente aquático do reservatório. Mas, somente algumas variáveis tiveram comportamentos parecidos nas campanhas temporais, como o caso da turbidez.

A variável turbidez foi a única que manteve comportamento idêntico nos períodos analisados (época chuvosa valores altos, época de estiagem valores baixos). Esta variável é a maior indicadora da entrada de sedimentos pela precipitação das chuvas. 
Algumas variáveis limnológicas, como $\mathrm{CE}, \mathrm{pH}$, e TDS, apresentam-se relacionadas entre si, pois se relacionam diretamente com a quantidade de íons presentes na água.

Todavia, as amostragens encontraram-se em consonância com a legislação, ou seja, as águas do reservatório estão em conformidade com a resolução CONAMA no 357/2005, e nenhuma variável teve os resultados acima dos limites estabelecidos.

Especialmente, a variável OD precisa ser acompanhada, pois a mesma foi a que mais variou no ambiente do reservatório, o que interfere diretamente na respiração dos organismos aeróbios, que sobrevivem precisamente na presença de oxigênio.

Os melhores resultados das correlações das avaliações limnológicas foram encontradas para os parâmetros de CE, TDS, $\mathrm{pH}$ e T, no período chuvoso de 2012, período com maior intensidade de chuva na bacia, o que contribui com a concentração de íons nos rios.

De acordo com análise espacial e temporal dos dados, as variações estão relacionadas ao tipo do uso da terra da bacia, e aos fatores litológicos, principalmente aos que são ricos em materiais carbonatos. O que contribui com a entrada de carbonatos, é a distribuição da precipitação ao longo do ano, e o transporte de sedimentos das bacias afluentes do reservatório.

\section{AGRADECIMENTOS}

Os autores agradecem aos órgãos de fomento desta pesquisa CAPES (bolsa de mestrado para o primeiro autor), CNPq (Processo 564525/2010-3), FAPEG (Processo: 201110267000114), pois esses financiamentos possibilitaram conduzir um trabalho desse porte.

\section{BIBLIOGRAFIA}

ALMEIDA, M. A. B.; SCHWARZBOLD, A. Avaliação sazonal da qualidade das águas do Arroio da Cria Montenegro, RS com aplicação de um Índice de Qualidade da Água (IQA). Revista Brasileira de Recursos Hídricos, v 8, n1, 2003, p.81-97.

ALVES, E. C. R. F. Monitoramento Quali-Quantitativo da Bacia Hidrográfica do Rio CoxipóMT: uma ferramenta para implementação da Gestão Participativa dos Recursos Hídricos. 283f. Dissertação apresentada ao Programa de Pós-Graduação em Física Ambiental da Universidade Federal de Mato Grosso - UFMT, Cuiabá - MT, 2009. Disponível em: <www.pgfa.ufmt.br/index.php?option=com_docman\&task..>. Acesso em: 19 abr. 2013. 
ANEEL, Agência Nacional de Energia Elétrica. Atlas de energia Elétrica do Brasil. 2a Edição. Brasília: ANEEL, 2005. 243p.

APHA; AWWA; WPG. Standard Methods for the Examination of Water and Wasterwater. American Public Health Association.19a Ed.-Washington D. C. 1995. 953p.

ARCOVA, F. C. S.; CESAR, S. F.; CICCO, V. Qualidade da água em microbacias recobertas por floresta de Mata Atlântica, Cunha, SP. Revista do Instituto Florestal, v.10, n.2, 1998. p.185196.

AWOMESO, J. A. et al. Studies on the Pollution of Waterbody by Textile Industry Effluents in Lagos, Nigeria. Journal of Applied Sciences in Environmental Sanitation. Vol. 5 no 4, 2010, p. 353-359.

BARCELOS, A. A. et al. Caracterizações físicas e químicas das águas dos afluentes da UHE Caçu. Revista GEONORTE, Edição Especial, V.3, N.4, p. 739-749, 2012. Disponível em: <http://labgeologiaambiental.jatai.ufg.br/pages/45000>. Acesso em: 14 jun. 2013.

CABRAL, J. B. P.; WACHHOLZ, F.; BECEGATO, V. A.; NASCIMENTO, E. S. Diagnóstico Hidrossedimentológico do Reservatório da UHE Caçu - GO. Geofocus (Madrid), v. 13, p. 2537, 2013. Disponível em: <http://geofocus.rediris.es/2013/Informe2_2013_1.pdf>. Acesso em: 14 jun. 2013.

CARVALHO, N. O. Hidrossedimentologia prática. 2. ed. rev., atual e ampliada. Rio de Janeiro: Interciência, 2008.

CETESB. Companhia Ambiental do Estado de São Paulo. Variáveis de qualidade das águas. Disponível em: <http://www.cetesb.sp.gov.br/agua/rios/variaveis.asp\#condutividade> Acesso em: 20 ago. 2013.

CONAMA, Conselho Nacional do Meio Ambiente. Resolução CONAMA $n^{\circ}$ 357, de 17 de março de 2005. Brasília, 2005. Disponível em: <http://www.mma.gov.br/port/conama/legiabre.cfm?codlegi=459> Acesso em: 10 mar. 2012.

EMBRAPA, Empresa Brasileira de Pesquisa Agropecuária. Sistema brasileiro de classificação de solos. Brasília: Embrapa. Rio de Janeiro: Embrapa Solos. 2009. 412 p.

ESTEVES, F. A. Fundamentos de Limnologia. Rio de Janeiro: Editora Interciência, 1998.

GASIM, M. B. et al. A Physico-Chemical Assessment of the Bebar River, Pahang, Malaysia. Global Journal of Environmental Research. Vol. 1 no 1, 2007, p. 07-11.

GERARDI, L. H. O; SILVA, B. C. N. Quantificação em Geografia. São Paulo: DIFEL, 1981.

GUERRA, A. J. T. (Org.). Um estudo do meio físico com fins de aplicação ao planejamento do uso agrícola da terra no sudoeste de Goiás. IBGE, Departamento de Recursos Naturais e Estudos Ambientais, 1989.

KIMMEL, B. L; LIND; O. T. PAULSON, J. L. Reservoir Primary Production. In: Reservoir Limnology: Ecological Perspectives. In: THORTON, K.W; KIMMEL, B. L.; PAYNE, F. E. New York: John Wiley and sons, 1990. p.133-193.

KLEEREKOPER, H. Introdução ao estudo da Limnologia. Ed. da Universidade Federal do Rio Grande do Sul - UFRGS, 1990. 182p. 
KOBIYAMA, M.; MOTA, A. de A.; CORSEUIL, C. W. Recursos hídricos e saneamento. Curitiba: Organic Trading, 2008. p. 160.

LATRUBESSE, E. M.; CARVALHO, T. M. Geomorfologia do Estado de Goiás e Distrito Federal. Goiânia, GO: Secretaria de Indústria e Comércio e Superintendência de Geologia e Mineração do Estado de Goiás, 2005.

LIMA, A. M. Relação clima e vegetação na área das bacias das usinas hidrelétricas de Barra dos Coqueiros e Caçu-GO. 89f. Dissertação apresentada ao Programa de Pós-Graduação em Geografia/PPG-GEO Stricto Sensu da Universidade Federal de Goiás - Campus Jataí/CAJ-UFG. GO, Jataí, 2013. Disponível em: < http://posgeo.jatai.ufg.br/uploads/180/original_Disserta\%C3\%A7\%C3\%A3o_Andreia_Medei ros_de_Lima.pdf>. Acesso em: 19 abr. 2013.

MARIANO, Z. F.; SANTOS, M. J. Z. ; SCOPEL, I. Variabilidade e tendência climática da região do Sudoeste de Goiás e sua relação com a cultura da soja. In: Seminário de Pós-Graduação em geografia da UNESP, 3, 2003, Rio Claro: Universidade Estadual Paulista, 2003, v. 1, p. 596616.

MORAIS, R. C. S.; SILVA, C. E. Diagnóstico ambiental do balneário Curva São Paulo no rio Poti em Teresina, Piauí. Eng. Sanit. Ambient. Vol.17 n.1, 2012. p. 41-50.

NOVELIS. RIA/RIMA UHEs Caçu e Barra dos Coqueiros. 2005. 230p.

PAULA, M. R.; CABRAL, J. B. P.; MARTINS, A. P. Uso de técnicas de Sensoriamento Remoto e Geoprocessamento na caracterização do uso da terra da bacia hidrográfica da UHE CaçuGO. In REVISTA GEONORTE, Manaus, V.4, n.4, 2012, p.1482 - 1490.

REBOUÇAS, A. C. Águas Doces no Brasil: Capital Ecológico, Uso e Conservação. 3ed. São Paulo: Escrituras, 2006.

ROCHA, H. M.; CABRAL, J. B. P.; BRAGA, C. C. Avaliação Espaço-Temporal das Águas dos Afluentes do Reservatório da UHE Barra dos Coqueiros/Goiás. RBRH - Revista Brasileira de Recursos Hídricos. Volume 19, n.1, 2014, p. 131-142.

SANTOS, C. Estatística Descritiva - Manual de Auto-aprendizagem, Lisboa: Edições Sílabo, 2007.

TUNDISI, J. G.; MATSUMURA TUNDISI, T. Limnologia. São Paulo: Oficina de Textos, 2008. 630p.

VON SPERLING, M. Introdução a Qualidade das Águas e ao Tratamento de Esgotos. 2a Ed. Belo Horizonte: Departamento de Engenharia Sanitária e Ambiental; Universidade Federal de Minas Gerais, 1996, 243p.

WETZEL, R. G. Limnology. 2 ed. Washington: Saunders College Publ., 1983. 919p.

\begin{tabular}{cc} 
Artigo submetido em & 23/07/2014 \\
\hline Artigo aceito em & 21/01/2015
\end{tabular}

